\title{
FRAGMENTOS DE UMA TEORIA CONSTITUCIONAL EM ROBERTO MANGABEIRA UNGER ${ }^{1}$
}

\author{
FRAGMENTS ON A CONSTITUTIONAL THEORY ON ROBERTO \\ MANGABEIRA UNGER
}

\author{
Arnaldo Sampaio de Moraes Godoy ${ }^{2}$ \\ "Portanto, abaixo os dogmas -- não só os deles, mas \\ também os nossos. É mais importante dar braços e asas à \\ energia frustrada da nação do que homenagear nossas \\ teses." \\ Roberto Mangabeira Unger, \\ Crescer sem Dogma, \\ Folha de São Paulo, 13 de março de 2007
}

\begin{abstract}
RESUMO - O ensaio tem por objetivo apresentar fragmentos conceituais de uma teoria constitucional em Roberto Mangabeira Unger. A proposta de Mangabeira centra-se em plebiscitos, na hipótese de impasses institucionais. Mangabeira propõe que exercitemos nossa imaginação, de modo que não nos apeguemos excessivamente na experiência dos antigos.
\end{abstract}

PALAVRAS-CHAVE - Impasse Institucional. Mangabeira. Plebiscitos. Teoria Constitucional.

ABSTRACT - The paper has the scope of presenting some conceptual fragment within the framework of an alleged constitutional theory on Roberto Mangabeira Unger. The proposal of Unger consists on plebiscites, in the case of institutional stalemate. Unger proposes us to enhance our imagination, in a way we do not lean strongly in the experience of our forefathers.

KEYWORDS - Unger. Constitutional Theory. Plebiscites. Institutional Stalemate.

O pensamento crítico ocidental conhece dois textos clássicos, escritos sob a forma de Teses. Refiro-me às Teses sobre Feuerbach, de autoria de Karl Marx, bem como às Teses sobre a Filosofia da História, de Walter Benjamin.

\footnotetext{
${ }^{1} \mathrm{O}$ ensaio tem por objetivo apresentar fragmentos conceituais de uma teoria constitucional em Roberto Mangabeira Unger. A proposta de Mangabeira centra-se em plebiscitos, na hipótese de impasses institucionais. Mangabeira propõe que exercitemos nossa imaginação, de modo que não nos apeguemos excessivamente na experiência dos antigos. Trata-se de estudos de pós-doutoramento na Universidade de Boston.

2 Doutor e Mestre em Direito pela Pontifícia Universidade Católica de São Paulo. ConsultorGeral da União. E-mail: asmgodoy@gmail.com.
} 
Sugiro a agregação de terceiro roteiro temático redigido em forma de Teses: as Teses de Democracia Radical, de Roberto Mangabeira Unger, ativista político brasileiro que leciona na Faculdade de Direito de Harvard, nos Estados Unidos. Mangabeira Unger é o mais conhecido intelectual brasileiro no contexto internacional, em âmbito de Ciências Sociais.

$O$ presente ensaio procura alcançar alguns fragmentos de uma teorização do direito constitucional em Roberto Mangabeira Unger, a partir de excerto que compõem conjunto de teses de democracia radical, no pensador aqui pesquisado. Aponta-se para um modelo centrado em plebiscitos, como técnica para superação de impasses.

Nas Teses sobre Feuerbach, de Marx, tem-se uma das mais vigorosas passagens do pensamento radical. Lê-se na tese XI, que "os filósofos até agora apenas interpretaram o mundo, de vários modos; agora é preciso transformáIo". E colhe-se na XIV Tese Sobre a Filosofia da História, de Walter Benjamin, o conceito de salto do tigre: apoderamo-nos do passado qual um animal predador, propiciando para nosso uso apenas o que nos interessa: Robespierre e a revolução francesa se viam como uma Roma reencarnada. Mangabeira é muito cauteloso para com a história, para com desavisado apego ao passado; não admite que sejamos servos fiéis de um pretérito que nós mesmos inventamos.

Roberto Mangabeira Unger radicalizou e realiza as teses de Marx e de Benjamin, incorporando-as e reelaborando-as em seu roteiro programático. Trata-se de filósofo que se propõe a transformar o mundo (e sua participação na vida política brasileira é da assertiva prova inconteste); e ainda, não se esconde em contexto de espera histórica, de atenção a leis prenhes de historicismo ingênuo. Recolhe esta historicidade cândida na vala comum das necessidades falsas, e apresenta programa de reforma. Propõe-se a ajudar a transformar o Brasil. E o direito constitucional pode ser instrumento desta grande mudança que Mangabeira propõe.

O seu programa temático encontra-se em forma de Manifesto, na segunda parte de seu livro Democracia Realizada- a Alternativa Progressista. Escrito originariamente em inglês, foi traduzido para o português por Carlos Graieb, Márcio Grandchamp e Paulo César Castanheira, em bem cuidada 
edição da Boitempo Editorial. É essa tradução que utilizarei, no que se refere à tese que proponho examinar. Quanto ao corpo do livro propriamente dito, as referências são da edição original.

São 13 teses, acomodadas em quatro campos conceituais: 1) a organização constitucional do governo e a estrutura legal da política eleitoral; 2) a organização da sociedade civil e a proteção dos direitos; 3) a organização das finanças públicas e da economia e, 4) a democracia e a esquerda.

Junto aos quatro grupos encontram-se os temas que animam as teses: 1) história das instituições democráticas; 2) estruturas constitucionais de governo; 3) reorganização da política eleitoral; 4) conceito de direitos fundamentais; 5) proteção dos direitos fundamentais; 6) organização legal da sociedade civil; 7) finanças públicas e sistema fiscal; 8) reforma do sistema produtivo e relação deste com o Estado; 9) direitos de propriedade; 10) significado de ser progressista hoje em dia; 11) interpretação da causa democrática; 12) base social aos partidos progressistas e, 13) foco da inovação institucional e do conflito ideológico no mundo. O presente excerto ocupa-se prioritariamente da segunda tese, das estruturas constitucionais de governo.

A linguagem de Mangabeira invoca grandiosidade e eloqüência; é densa e poderosa. Mangabeira quer ajudar a mudar o Brasil. Insiste que é momento de se acender a chama da paixão. Deve-se produzir luz e calor. Obstáculos que parecem intransponíveis serão reduzidos a cinzas, e a admoestação é literal. Não há limites. Deve-se imaginar a experiência daqueles que poderíamos ter sido, sugere a metafísica revolucionária do professor brasileiro que leciona em Harvard. Na mesma linha, de pugna, quer que morramos apenas uma vez, como se morre na guerra, ao invés de morrermos recorrentemente, muitas mortes sem grandeza.

O Manifesto de Mangabeira, de onde retiro os referidos fragmentos de uma teoria constitucional, encaixa-se na tradição radical do pensamento moderno e contemporâneo. Essa tradição remonta a Rousseau, e refiro-me especialmente ao prefácio e a segunda parte do Discurso sobre as Origens e Fundamentos da Desigualdade. Voltaire, no Dicionário Filosófico, no verbete politique, retomou essa linha de pensamento. 
Thomas Jefferson sumariou os direitos das colônias norte-americanas, pugnando por fraternidade e harmonia. Jefferson parecia partidário do experimentalismo; sua concepção de reforma constitucional permanente influencia o ideário de Roberto Mangabeira. Essa tradição política de concepção de manifestos também é encontrada em Thomas Paine, que no apêndice de seu Common Sense referia-se a direitos da humanidade e a estados livres e independentes na América.

A declaração de independência dos Estados Unidos, de 4 de julho de 1776, levou ao limite (à época) concepção de que verdades auto-evidentes dariam conta de que os homens nascemos iguais e que somos dotados pelo Criador com direitos inalienáveis, a exemplo da liberdade, da vida e da busca da felicidade. Do outro lado do Atlântico, na França, Camille Desmoullins dava continuidade à tradição, insistindo que a única alternativa à perda de liberdade seria a morte. O Abade Sieyès recolocou o problema em termos de classe social. Jean Paul Marat e Georges Jacques Danton radicalizaram projetos revolucionários, percepção levada ao limite por Pierre-Sylvain Marechal e por Babeuf.

Proudhon também se filiou a essa tradição, e afirmou que a propriedade é um roubo. Marx e Engels conclamaram a união dos proletários. Ferdinand Lassalle concebeu um programa do trabalhador. Kropotkin apelou para os jovens. Bakunin substancializou críticas à religião e ao Estado. Trotsky vinculou proletariado e revolução, de modo permanente. Emma Goldman apontou tragédias que decorrem da condição feminina. Mangabeira é integrante dessa tradição revolucionária. E seu pensamento é dirigido para nossa condição de pais periférico, sem deixar de ser um ideário marcadamente universal.

Mangabeira tem a ambição de reunir investigação especulativa, pesquisa acadêmica, pensamento programático e luta transformadora (cf. TRUBEK, 1990, p. 232 e ss.). Pretende transformar a política em arena para prática da fé, da esperança e da caridade. Integrando jornalismo e política, remete-nos à tradição norte-americana dos Federalist Papers. Os Federalist Papers consistem em 85 ensaios de autoria de Alexander Hamilton, James Madison e John Jay, publicados na década de 1780, nos Estados Unidos, com o objetivo de convencer os norte-americanos a adotarem a constituição que se 
discutia. Formam o mais completo corpo conceitual de defesa do modelo político dos Estados Unidos.

Para Mangabeira, "nosso salvamento está dentro de nós". Antes que essa alforria exista como política e economia, precisa viver como comoção e idéia. Enuncia princípios que colocam a democracia social ao lado das forças inconformadas, impacientes e criadoras. Segundo Mangabeira, "em época de democracia, a profecia fala mais alto do que a memória".

Seus planos transitam do cosmopolitismo para o endógeno, do internacional para questões caipiras, marcas de país que se diz "avesso à guerra, mas que é acostumado à violência". Uma estratégia nacional compatível com os interesses brasileiros deveria nortear nossos passos para com a globalização. Teríamos mais condições de sucesso do que muitos outros países continentais, a exemplo da Índia, da China, da Indonésia e da Rússia. Deveríamos globalizar de nosso modo. A busca da globalização que nos convém reverte o quadro patológico da "humanização do inevitável".

São muitos os assuntos que Mangabeira apreende em seu Manifesto. E são temas que acenam com projeto radical, por vezes plasmado como utópico, na tradição que remonta a Pierre-Joseph Proudhon. Mangabeira repudia a presunção comum de que há terceira via factível e alternativa à ambigüidade do neoliberalismo e à imprestabilidade histórica do socialismo real. O pensador brasileiro insiste que hoje só há uma via, e que a essa senda é que se deve propor novo caminho. As teses pretendem uma direção. Propõe-se esquema de enfrentamento às superstições falaciosas que marcam o pensamento político contemporâneo, ainda afetado por questões levantadas pelo positivismo formalista do século XIX.

Pretende-se alternativa para tradição constitucional que se vê como o ápice de lenta e custosa evolução. Indica-se alternativa de fragmentação de poderes, suscetível de transcender aos impasses da formulação clássica de Montesquieu. Reformas constitucionais são necessárias, e desejáveis: textos constitucionais não são documentos canônicos. Deve-se fomentar a participação política. Mangabeira parece acenar com saudosismo ao constitucionalismo plebiscitário de Weimar. Reformas que demandam legislação têm preferência em face da normatividade cotidiana e episódica. 
Referendos e plebiscitos poderiam fazer frente ao impasse recorrente do modelo constitucional centrado na legalidade absoluta. Para Mangabeira, campanhas políticas exigem financiamento público. Deve-se disciplinar a escandalosa e incestuosa relação entre partidos políticos e meios de comunicação.

O programa de Mangabeira também sugere modelo de interpretação de direitos fundamentais. Pragmatismo normativo e realismo jurídico se aproximam. Mangabeira discute o problema do direito sucessório, o que o coloca em sintonia com a tradição de Proudhon. Educação e capacitação genérica devem ser opostas ao modelo finalista de reprodução de operáriopadrão. Nas teses se percebe a emergência de um novo poder estatal. No estilo grandioso que marca sua escrita, Mangabeira mantém retórica que "convoca os espíritos".

Mangabeira se irrita com as Ciências Sociais que triunfam no Brasil, e que se limitam a explicar a necessidade do que já existe. Insurge-se contra resíduos fossilizados de teorias deterministas que vêem os indivíduos como joguetes de forças coletivas. Nesse sentido, abomina o marxismo conceitual, dogmático. Não confunde compromissos programáticos com dogmas intelectuais.

Creio que o tema democracia radical já freqüentava o ideário de John Dewey, nome mais marcante do pragmatismo norte-americano. Para Dewey, a finalidade da democracia é radical; ninguém ainda realizou-a (cf. DEWEY, 1998, p. 338). Alcanço aí a importância do projeto de Mangabeira. Ciente dos altos e baixos do liberalismo e do socialismo real, Mangabeira avançou de modo muito ambicioso, e nos propõe programa factível para nosso tempo e vidas.

Sigo com a segunda tese enunciada por Mangabeira, denominada Das estruturas constitucionais do governo, cujo comentário é o eixo temático do presente ensaio:

Um estilo constitucional projetado para acelerar a política e favorecer a prática repetida e freqüente de reforma básica deveria combinar um forte elemento plebiscitário com uma ampla faixa de canais para a representação política da sociedade. Por exemplo: um parlamento forte coexiste com um presidente eleito em pleito direto, com substanciais poderes de iniciativa política. Mas o modelo padrão híbrido de regime presidencial e parlamentar (como na Constituição 
da Quinta República) é substituído por um sistema que evita o governo fraco e a perpetuação do impasse. Esse sistema funciona de acordo com os princípios enumerados a seguir. Primeiramente, os programas de reforma gozam de prioridade sobre a legislação episódica ordinária; esses programas precisam ser aceitos de comum acordo, rejeitados, ou negociados rapidamente. Em segundo lugar, sob til. sistema, se o presidente e o parlamento não estão de acordo quanto ao programa de reforma, podem concordar com a realização de plebiscitos ou referendos. Em terceiro lugar, se os poderes políticos do Estado não conseguem chegar a um acordo a respeito da realização ou dos termos de uma consulta popular, ou se o resultado da consulta não for decisivo, então o parlamento ou o presidente podem convocar eleições antecipadas, mas as eleições devem ser simultâneas para ambos os setores do governo. O princípio geral é uma solução rápida do impasse por meio de um envolvimento direto do eleitorado geral. O objetivo é acelerar o experimentalismo democrático, facilitando a prática repetida da reforma radical: mudança nas instituições e práticas formadoras da sociedade, bem como das crenças estabelecidas nas quais elas estão inseridas. Em muitos países, com partidos políticos fortes e eleitorado beminformado, a reforma de um sistema parlamentar de governo pode produzir resultados semelhantes. (MANGABEIRA UNGER, 1999, p. 208).

A tese de Mangabeira acima enunciada assenta-se em mecanismo de participação plebiscitária, idéia que é recorrente no pensamento do autor aqui estudado. Não obstante a menção expressa ao constitucionalismo francês, o referencial é extensivo ao modelo constitucional alemão do entre - guerras, tal como construído em Weimar, sob a liderança de Hugo Preuss, e com alguma influência de Max Weber.

À época, parecia triunfar uma esquerda liberal, dirigida pelo próprio Hugo Preuss e por Hans Kelsen, que era juiz e ensinava em Viena. Concebeuse uma constituição soberana, de forte inspiração popular, com estações conceituais em Georg Jellineck e em Gerhard Anschütz.

As idéias desse grupo associavam-se ao pensamento de Rudolf Smend e de Heinrich Triepel, para quem a constituição encetava valores invioláveis da comunidade. Herman Heller, identificado com a social-democracia, propunha texto constitucional como garantidor social. À direita, emergia noção mais substancial de Volk, com poderes de decisão que transcenderiam ao caos e à emergência. Seu representante maior foi Carl Schmitt, que polemizou com Kelsen, e que se identificou com o nazi-fascismo que lá brotou (cf. CALDWELL, 1997). 
A República de Weimar conheceu governos em permanente estado de crise (cf. MOMMSEN, 1996, p. 357 e ss.). Um pluralismo partidário excessivo teria potencializado desintegração que ensaiou ao longo de toda a década de 1920 (cf. KOCH, 1984, p. 278). O art. 73 da Constituição de Weimar previa que o Presidente poderia submeter ao povo a aprovação de qualquer legislação, por plebiscito, antes da promulgação da lei que se discutia (cf. HUCKO, 1989, p. 165). Em contrapartida, previa-se grande parcela de poder ao Presidente, que nos termos do art. 48 daquele texto constitucional poderia tomar medidas discricionárias, inclusive mediante o uso das forças armadas (cf. HUCKO, cit., p. 160).

A tese plebiscitária, em favor de mecanismo que suscite resolução de impasses, e que tem antecedentes no modelo do pós-guerra francês e no modelo do entre - guerras alemão, identifica força inspiradora das propostas de Mangabeira. Concomitantemente, alcança-se o processo legislativo, na medida em que se propõe preferência para o encaminhamento e processamento de reformas de fundo, em desfavor de produção normativa episódica.

O processo legislativo brasileiro (art. 59 e ss. da constituição de 1988), e que compreende a elaboração de emendas à constituição, leis complementares, leis ordinárias, leis delegadas, medidas provisórias (que indevidamente copiamos da Itália), decretos legislativos e resoluções, em princípio, qualificaria obstáculos à proposta, a menos que modelos de plebiscitos e de referendos pudessem intervir adequadamente. No entanto, ainda restaria espaço para discussão, e eventualmente para impasse, dado o controle de constitucionalidade de leis, exercido pelo judiciário em geral, de forma difusa, e pelo Supremo Tribunal Federal, em especial, de forma concentrada.

Em outras palavras, poderia o Supremo Tribunal Federal declarar inconstitucional uma norma aprovada por mecanismos de plebiscito e de referendo? A questão não é acadêmica, e freqüenta a discussão constitucional norte-americana, por exemplo. É que, dado que não há previsão expressa na constituição dos Estados Unidos, outorgando com todas as palavras ao poder judiciário o poder de declarar a inconstitucionalidade de leis, construiu-se doutrina indicativa de que controle de constitucionalidade consubstanciaria 
engenharia normativa contra-majoritária. $\mathrm{O}$ debate é longo, e radica, de certa maneira, no caso Marbury v. Madison, de 1803.

No que se refere ao alcance do plebiscito e do referendo, no caso brasileiro, há ainda o conjunto normativo que informa as cláusulas pétreas, ou o bloco constitucional sensível, tal como enunciado no $\S 4^{\circ}$, do art. 60 , da constituição de 1988, e que veda deliberação de proposta de emenda tendente a abolir a forma federativa de Estado, o voto direto, secreto, universal e periódico, a separação dos poderes e os direitos e garantias individuais.

Do ponto de vista dogmático propostas de nova sistemática de fracionamento de poderes encontrariam resistência no próprio texto constitucional. E não há subterfúgio em jocosa lembrança que nos daria conta de que para toda cláusula pétrea haveria uma emenda britadeira...

O baixo envolvimento do eleitorado brasileiro no processo político é questão clássica, e recorrente, em nossa estrutura republicana. Além disso, “(...) o comportamento eleitoral conservador, clientelista e deferente em relação aos chefes políticos locais, expresso no voto situacionista, tem caracterizado principalmente as camadas urbanas mais marginalizadas e especialmente os setores mais pobres da população das zonas rurais e das pequenas cidades do interior, principalmente das regiões mais atrasadas do país" (cf. CASTRO, 2004, p. 291).

Essa baixíssima participação qualifica a inexpressiva expressão do interesse local, no debate das causas nacionais, e que são em última instância ontologicamente locais. Nesse sentido, o estudo de Victor Nunes Leal, e a denúncia do coronel, o manipulador de vontades eleitorais:

Qualquer que seja, entretanto, o chefe municipal, o elemento primário desse tipo de liderança é o 'coronel', que comanda discricionariamente um lote considerável de votos de cabresto. A força eleitoral empresta-lhe prestígio político, natural coroamento de sua privilegiada situação econômica e social de dono de terras. Dentro da esfera própria de influência, o 'coronel' como que resume em sua pessoa, por exemplo, uma ampla jurisdição sobre seus descendentes, compondo rixas e desavenças e proferindo, às vezes, verdadeiros arbitramentos, que os interessados respeitam. Também se enfeixam em suas mãos, com ou sem caráter oficial, extensas funções policiais, de que freqüentemente se desincumbe com a sua pura ascendência social, mas que eventualmente pode tornar efetivas com o auxílio de empregados, agregados ou capangas. (LEAL, 1978, p. 23) 
A solução de impasses pelo eleitorado, muito menos do que instrumento de resolução de problemas, exige eleitores dispostos e interessados, conscientes do valor que o sistema outorgaria à decisão que tomassem. Mantidas as condições atuais, com mera atualização tecnológica dos mecanismos denunciados por Victor Nunes Leal, o que se alcançará será a multiplicação de programas eleitorais, dirigidos por marqueteiros, fazendo-se do político uma mistura bem engendrada de ingredientes que qualificam os heróis da mídia.

Mangabeira sugere que devamos discutir a estrutura constitucional dos governos centrais; em nenhuma área é maior nossa dependência para com tradição conceitual monolítica. Circunstancialmente somos prisioneiros de idéias que marcaram o debate político nos fins do século XVIII e no início do século XIX. E de tal modo, acabamos convencidos de que essas idéias substancializam o que há de melhor no conjunto conceitual da democracia liberal, protagonizando-se ainda outro capítulo da narrativa mitológica do avanço democrático.

Especialmente após a queda dos regimes socialistas ao longo da década de 1990 esse modelo de persuasão funcionou perfeitamente; exemplo mais eloqüente encontra-se em Francis Fukuyama, que posteriormente, no entanto, deixou de fazer apologias ao triunfo do liberalismo ocidental (cf. FUKUYAMA, 2006). O constitucionalismo liberal é historicamente instrumento em favor de privilegiados, de notáveis; tenta-se obstruir a participação das massas e dos demagogos (cf. MANGABEIRA UNGER, 1997).

A democracia radical, tal como engendrada nas teses de Mangabeira, articularia alternativa para o modelo elitista com o qual se conta. E Mangabeira percebeu elo perdido, e esquecido na tradição que remonta ao modelo da constituição de Weimar; lembra-se de uma esquerda hesitante e embaraçada, com a qual se identificavam Hugo Preuss e Hans Kelsen. Tentava-se reagir em face de um passado imediato, representado pelo autoritarismo da Alemanha guilhermina e bismarquiana.

Lutava-se contra um executivo autoritário. Tentava-se racionalizar o governo, e certa seria a influência de Max Weber (cf. MOMMSEN, 1990). 
Buscava-se identificar o centro do poder governamental para, em seguida, conseguir-se fórmula legal para discipliná-lo. Posteriores alterações políticas promoveram a revisão desses textos constitucionais. De um lado, observou-se mudança no balanço político, em favor da direita. Foram adotados modelos dualísticos, com dois poderes eleitos por sufrágio direto; quebrava-se 0 monopólio com adoção de convívio entre parlamento e presidência (cf. MANGABEIRA UNGER, 1997).

À época, primeira metade do século $X X$, especialmente em sua segunda década, tentava-se maximizar aspectos populares da democracia indireta. Concomitantemente, outorgava-se ao governo poder de iniciativa decisional. No entanto, o modelo não permitia ameaça à primazia do apelo às massas. Impasses eram resolvidos mediante eleições gerais. Esse modelo fora utilizado pela constituição portuguesa de meados da década de 1970 (cf. MANGABEIRA UNGER, 1997).

Observe-se que essas premissas e circunstâncias não se aplicam ao modelo brasileiro. A nossa constituição de 1891 era elitista, desprestigiava a população humilde, vedava o voto aos analfabetos e às mulheres. A reforma de 1926 não substancializou nenhum avanço. O poder era monopólio dos coronéis ligados à posse da terra; aos estados produtores de café revezavam-se na presidência da República, com apoio indiscreto dos governadores estaduais.

O golpe de 1930 (que levou para o exílio o avô de Roberto Mangabeira Unger, Otávio Mangabeira, que fora ministro das relações exteriores de Washington Luís), e a superveniente constituição de 1934, não alteraram esse estado de coisas, com exceção do voto feminino que, de resto, não fora de imediato implementado, por conta do golpe de 1937.

A ditadura que sobreveio, bem como o modelo populista que emergiu institucionalmente da carta de 1946, não corrigiram essas disfunções. Digo o mesmo do texto constitucional de 1988, não obstante a aura de verticalidade democrática que se the tenta imputar, por parte dos constitucionalistas brasileiros mais convencionais.

O sentido absolutamente referendário e plebiscitário que emerge da tentativa de localização de um fragmento de teoria constitucional em Roberto 
Mangabeira Unger, em princípio, encontraria obstáculos abstratamente intransponíveis na ordem constitucional brasileira contemporânea.

No entanto, como a imaginação institucional e a plasticidade dos mecanismos políticos precisam orientar a ação do político inconformado é que se deva insistir em reformas centradas na agenda radical do pensador aqui estudado.

\section{REFERÊNCIAS}

CALDWELL, Peter C. Popular Sovereignty and the Crisis of German Constitutional Law- The Theory and Practice of Weimar Constitutionalism. Durham: Duke University Press, 1997.

DEWEY, John. The Essential Dewey. Volume 1. Pragmatism, Education, Democracy. Ed. Larry A. Hickman e Thomas M. Alexander. Bloomington: Indiana University Press, 1998.

FUKUYAMA, Francis. America at the Crossroads. New Haven: Yale University Press, 2006.

HUCKO, Elmar M. The Democratic Tradition. Oxford: Berg, 1989.

KOCH, H. W. A Constitutional History of Germany. Londres: Longman, 1984.

LEAL, Vitor Nunes, Coronelismo, Enxada e Voto, São Paulo: Alfa-Ômega, 1978.

MANGABEIRA UNGER, Roberto. Democracia Realizada - a Alternativa Progressista. Tradução de Carlos Graieb, Marcio Grandchamp e Paulo César Castanheira. São Paulo: Boitempo Editorial, 1999.

MANGABEIRA UNGER, Roberto. Democracy Realized, the Progressive Alternative. London and New York: Verso, 1996.

MOMMSEN, Hans. The Rise and Fall of Weimar Democracy. Chapel Hill: University of North Carolina Press, 1996.

TRUBEK, David M. Programmatic Thought and the Critique of the Social Disciplines, in Robert Lovin e Michael Perry, Critique and Construction- a Symposium on Roberto Unger's Politics. Cambridge: Cambridge University Press, 1990.

WEST, Cornell. Between Dewey and Gramsci: Unger's Emancipatory Experimentalism, in Robert Lovin e Michael Perry, Critique and Construction- a 
Symposium on Roberto Unger's Politics. Cambridge: Cambridge University Press, 1990.

Recebido para publicação: 17/10/2011

Aceito para publicação: 09/08/2012 